$$
\begin{array}{r}
S B 389 \\
\cdot N 65
\end{array}
$$



REPORT ON WINES-ROCHESTER, 1864.

New Yorb slete arriouelumal pocity
SUPPLEMENTARY REPORT

OF A PART OF THE

COMMITTEE ON WINES

A'T THE

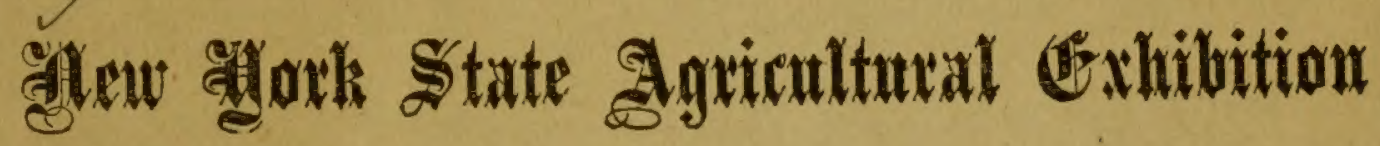

At Rochestex, 1864 .
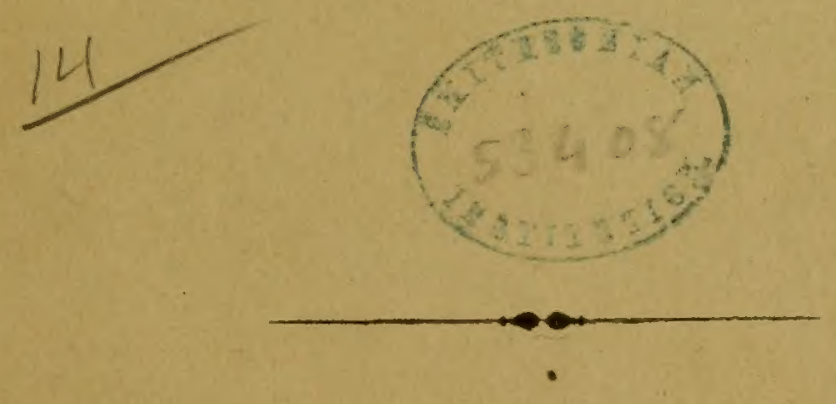

ALBAN $\mathrm{Y}$ :

VAN BENTHUYSEN'S STEAM PRINTING HOUSE.

1865 . 



\title{
REPORT ON WINES-ROCHESTER, 1864.
}

\author{
Supplementary Report of a part of the Committee on Wines at the New York \\ State Agricultural Exhibition at Rochester, 1864.
}

The undersigned have, on several occasions, been associated in committees for the examination of domestic wines under the appointment and direction of this Society during the past fifteen years. They have watched the progress of wine-making from its household production, composed of various of the smaller fruits-such as the currant, gooseberry, \&c, as well as the grape, up to the wines from the estabiished wine-producing vineyards.

All these household varieties of so-called "wines" have appeared at the annual exhibitions, and of the same general character, to wit : the expressed juice of the several fruits by the names of which they are called as prefixed to the article, as "Currant," "Gooseberry," "Blackberry," "Raspberry," \&c., wines. They have been of abont the same character and quality-some better than others, but all lacking the essential table and long-keeping qualities of true grape wines. Composed as they are (in addition to the juices of their fruits, ) of water, sugar, and sometimes spirits, or alchohol, in their various cooking processes to complete their manufacture, we cannot call them wines, as usually understood. They are really cordials, excellent in their way, both useful and ornamental appendages to household luxury and social entertainment.

We would not by any means discourage the making of these cordials as beverages; they are agreeable to many tastes, and harmless in their effects. They interest the attention of the wives and daughters of our farmers as well as other rural and village residents; are incentives to their ingenuity and promotive of a commendable rivalry in household production. They are articles in which all generous natures love, more or less, to indulgelaudable illustrations of female hospitality - a virtue like "a soft, gentle, and low voice;" as in Lear's Cordelia_" an excellent thing in woman."

Household productions of this description, we respectfully recommend. should hereafter be placed at the Society's exhibitions in a class by themselves as " cordials," rather than wines. They are not articles of the same character, in reality, although some of them be made chiefly of the grape, as they bear no commercial, or even consumptive relation to the products "proper" of the vineyard.

\section{WINES PROPER.}

The grape for the manufacture of wine has made considerable progress in its cultivation in the State of New York during the last ten years-the success which has attended wine production in some of the Western States 
having stimulated its production here. As a general fact, our climate is too cold for the perfect production and maturity of the most successful wine grapes grown for that purpose in our best wine-producing States in the Mississippi Valley. Their warm season is longer, and their temperature higher than our's, and the grapes from which their best wines are made, as the Catawba, Isabella, and other varieties usually grown there, perfect their qualities better than with us. We, therefore, as a rule, labor under a disadvantage in the production of wines of equal quality with theirs. Such, however, although it be a defect with those varieties of grape, need not prevent the wine-growers of New York from further trials with new varieties, which are well suited to our climates and soils, to achieve ultimate success in the production of wines of high quality and. profitable sale.

GRAPE SOILS.

Facts, which have come within the cognizance of your Committee during several years past, and which may readily escape the ordinary observer, demonstrate that portions of our State may be made productive of good wines from grapes congenial to their soils, and developing their full qualities of excellence in our climate. Soil, altitude, position-topographical or geographical - the contiguity of hills, mountains, or considerable bodies of water, freedom from currents of the winds, \&c., are, perhaps, the controlling features which render certain localities particularly favorable to the growth of the grape more than others, in foreign countries where wine is a leading article of production. The experience of our own grape cultivators has proved it none the less so in this country. In several countries of Europe, some of the choicest varieties of their wines are produced only on a few contiguous acres occupying a marked pcsition; while in the same vicinity, and but a little distance away, the same grape with the same cultivation produces an inferior wine; such are the Chateaux-Margaux, Champagne, Tokay, Johannisberg, and others-the true wines of which, although closely imitated in other localities, are never approached in the peculiar, distinctive and excellent qualities of the originals.

Such we are rapidly finding to be the case in America. Some peculiar quality of the soil in these spots is probably the cause of this difference in Europe. It may be equally so in America. Yet, with us, more marked differences exist. In one locality the grape flourishes and arrives at a high degree of perfection in its qualities, while in another locality of different altitude, or position of relative surroundings the same grape will scarcely grow or ripen at all. Familiar instances of such character are well known, as in the valley of the Hudson, or the south shore of Lakes Ontario and Erie, and the shores and vicinities of the interior small lakes of Western New York. These may prove successful points of vineyard production in the future when planted with varieties of grape congenial to their soils, while throughout their intermediate regions the same fruits will scarce repay their cultivation.

VARIETIES OF GRAPE.

The American wine producer has had, for the most part up to the present time, but a blind and difficult path before him in which to achieve any con- 
siderable degree of success. The European grape, although largely introduced here in numerous varieties in open ont-door culture, has proved a signal failure. It mildews. Though apparently successful for a time in some localties, its ultimate failure has been certain and its growth abandoned. We have, therefore, been obliged to rely solely on grapes indigenous to the soil, and these few in variety. The two leading grapes to which our attention has been directed for years has been the Catawba and Isabella, both of Carolina origin as supposed, and requirirg long, hot summers to perfect their qualities. Although ranking high as table grapes, their vinous qualities have been in chief request, and they have not developed their full excellence in this State above the Highlands of the Hudson river, or latitude $41 \frac{1}{2}$ north. It is true that specimens of high quality have been produced north of that parallel, but they have been specimens only. They are the exception, not the rule; although the Isabella in particular has been largely cultivated. Not one year in four have they thorougly ripened as they do below the Highlands; where between Peekskill and Sandy Hook they are grown to their highest perfection; better even than at Cincinnati, two degrees of latitude further south. A strange feature in the Catawba grape has been developed within the last ten years. It was for a long time supposed that the neighborhood of Cincinnati was its peculiar home: that it there matured its qualities in a superior degree over any other point north. There lie a cluster of islands in Lake Erie near its westerly boundary, six or eight miles northerly of its southern boundary on the peninsula of Sandusky Bay in Ohio, under the names of "Kelly's," "Putin-bay," and the Bass Islands. These islands are exposed to all the inclemencies of a latitude 200 miles north of Cincinnati, their soils a stiff clay loam, rich in quality, resting on a shelly lime rock, one to six feet below. Into these islands the Catawba grape has been introduced, and its fruit exceeds in flavor and its wine in quality that produced in Cincinnati. The Isabella, and all the new varieties of native grape-of which latter Kelly's Island has produced several-are equally superior. This fact demonstrates, palpably, that climate alone does not control the quality of the grape. Another strange feature of these islands is, that although exposed to all the inclemencies of an open lake 300 miles long and fifty miles broad, the spring is several days earlier there than on the south shore of the lake in the region of Sandusky. Subsequent trials have also established the fact that for many miles along the main Ohio shore nearest these islands the Catawba and Isabella grapes grow in high perfection, and the land is being rapidly appropriated to vine cultivation for wine purposes. How far these discoveries are to be extended in that vicinity is yet to be known.

Your committee are aware that a portion of the above remarks are not strictly applicable to the subject of New York wine culture, but as they embody facts which may find their parallels with us, we have not deemed them altogether out of place in this report. To relieve the difficulty heretofore existing in the want of varieties of grape adapted to our climate and soils, the attention of our Northern vine growers has been directed for several years past to hybridizing the fruit of our established kinds, and producing from their seeds new varieties. In this they have been most successful, although with some of them, as the Delaware and a few others, 
their parentage is not distinctly settled. With others, their origin has been satisfactorily established, and from the adaptation of several of the new kinds to our soils and climate, together with the favorable promise of some others, we have little doubt that we are fast approaching the time when New York will abound in several varieties of grape from which, even in our comparatively high latitude, may be produced large quantities of wine, valuable not only for domestic consumption, but in some extent to supply the demands of commerce. The Hartford Prolific, Concord, Delaware, Diana, Clinton, Allen's Hybrid, are already established as suitable to our climate, in general, while some others of more recent introduction are on trial, and may be equal, or even superior in various qualities, to those already proved. The Catawba and Isabella, even, although the most tardy of the better grapes, do ripen, as is claimed by their cultivators, in certain localities of our State above latitude $41 \frac{1}{2}$; and excellent wines and brandies have been made from them at Pleasant Valley, at the head of Crooked Lake, in the county of Steuben, for example; but the committee have not ascertained that the full perfection of their qualities in the secretion of grape sugar and the concentrated maturity of the fruit, only to be obtained from the long shining of an October sun in a mild atmosphere, has been altogether developed, as at Kelly's Island and Cincinnati.

VARIETIES OF WINE FROM OUR NATIVE GRAPE.

The kinds of wine chiefly yet produced from our native grapes have been the light, dry, still wines, and the "sparkling" similar to the effervescing "Hocks" of Earope. The Isabella and Catawba grapes have both produced the former, and the Catawba, mainly, the latter. Some other varieties have produced wines of somewhat like character, but they have been tried mostly as experiments. We saw a sample of still wine at the late exhibition in Rochester, made by M Brehm*, a young farmer located at Lyons, Wayne county, N. Y., from the Diana, which we considered equal to any American wine within our knowledge. The wines of the Pleasant Valley Wine Company before named, were also good of their kind. They showed at Rochester the "still" and the "sparkling" wines; also imitations of Claret and Port wines in color, and quite tolerable in taste, both from the Catawba and Isabella grape; and we think, had the warm season been longer, and the grapes still riper than they had time to become in their locality, the wine would have been better. Our opinion, most decidedly, is that those two grapes, even in so favorable a place as Pleasant Valley, will be superseded by earlier varieties, which, if not now in existence, will yet be discovered or invented.

The early grapes which we have named have not yet been tried to a sufficient extent to prove thoroughly their wire-producing qualities. They have chiefly been tested and judged as table grapes; and on this virtue their merits have been properly decided. They have as yet been but partially tested for wine, and when properly done, may prove all that is needed in that particular. Nor do we consider that the edible qualities of the grape are at all to govern their qualities for wine. The astringent, 
harsh and offensive taste of a grape may render it worthless for the table, and these offensive qualities, when properly commingled in the press and vat, may be all the better for wine. It is so with some European varieties, and why may it not be with American? We are yet neophytes in both grape culture and wine-making in New York, and hardly beyond that, with the exception of what may be termed "common wines," in any part of America. We have known the Cincinnati and other Western wines for years. They are good, of their kind, and will undoubtedly become of extended production and increased consumption to an indefinite degree. But we have yet to see anything like an approach to the Sherries, the Madeiras, the genuine Champagnes, the Clarets, the Ports, and many other of the choice wines of Europe, and dare not predict the day when they will be produced on this side of the Atlantic. It is not yet ascertained that we possess the combinations of soil and climate to produce them. The grapes that produce them there will certainly not produce them here; and if we ever do produce those wines, the grapes to make them have yet to be invented.

So successful have been the effurts of the Pleasant Valley Wine Company in the cultivation of the grape and the production of wine in their favored locality, and so much gratified were your committee with their samples of the grapes and wines at the Rochester exhibitions of 1862 and 1864-at both of which we officiated as judges of their articles-that we appointed a time, and intended to make a visit there for our personal inspection in October last; but our domestic engagements and the extremely unfavorable state of the weather prevented. To supply this deficiency, however, we have the opportunity of laying before you a timely report of "Pleasant Valley," made by Hon. Henry S. Randall LL. D., to the Rural New Yorker in November last, which embodies the essential part of the information we desired. It is of such interest in developing the progress of wine culture in our State, that we ask its insertion as a part of our report.

The Vineyards and Wine Manufactures at Pleasant Valley, N. Y., by Henry S. Randall, LL. D.

"On a pleasant forenoon towards the close of October, General O. F. Marshall and myself left his residence in Wheeler, Steuben county, on a visit to our good friends, Aaron Y. Baker, Charles D. Champlin and Gratton $\mathrm{H}$. Wheeler. After proceeding several miles and surmounting a ridge of hills, we looked down their eastern slopes on a comparatively level valley about three miles long and one wide. North of it Crooked Lake fills the chasm between the hills; south the land becomes broken and elevated. The ridge of hills which hem in the valley on the east and west are about one thousand feet high. The eastern and much of the western range are yet covered with pine, oak and chestnut; the dark green, crimson and russet verdure of which, touched by the October frosts, contrasted finely with the emerald hue of the grass; and, on the whole, I decided in my own mind that Pleasant Valley is not a misnomer for the region which was lying under my eye. The village of Hammondsport is situated at the head of the lake. It is seven hundred feet above tide water. A steamboat plies between it and Penn Yan. 
"Isabella and Catawba grapes were introduced into Pleasant Valley about thirty years ago by the Rev. Wm. Bostwick, and were found to fiourish admirably; to be quite as sure, if not surer, than any farm crop, and to be wholly unsubject to disease of any kind.

"In 1853 or 1854, Andrew Resinger, a German vine-dresser, came into Pulteney, eight miles north of Hammondsport, and planted about an acre and a half of the hill-side on the banks of the lake with Catawbas and Isabellas-mostly the former. The soil was a heavy clay, and he trenched it in the German mode two and a half feet deep. Resinger's experiment was rather a failure, and was ultimately abandoned by him. But in the year 1855, Orlando Shepherd and Judge Jacob Larrowe, finding how well grape culture succeeded at Avon, in Livingston county, brought vines from there to Pleasant Valley, and set out about half an acre each on the hill-side near Hammondsport.

"The minds of the people in the Valley have received a strong impetus towards grape culture from several causes. The first of these was the uniform prolificacy and excellence of the grape on their lands under almost any treatment; second, the great success and profits of Longworth and others at Cincinnati in its culture, and the example already named nearer by in Avon, and also that of a Mr. McKay, of Naples, Ontario county, who had cultivated a vineyard of several acres from about 1848 with great profit; and finally the agricultural newspapers at that period were specially engaged in calling attention to the subject. An influx into the neighborhood of industrious and honest German emigrants familiar with grape culture and wine-making gave the people an opportunity to obtain further information on the subject. They became satisfied that their soil and climate were adapted to that culture, and the Germans supplied them with experienced laborers. They, therefore, did not wait the result of Shepherd's and Larrowe's experiment. In 1858, both of these gentlemen increased their vineyards to two or three acres each; Bell \& McMaster set out six or eight acres of vines; Gratton H. Wheeler, four acres; Edwin P. Smith, two acres; Charles D. Champlin, one acre; Stanley B. Fairchild, one acre; and Timothy M. Younglove, one acre.

"In the fall of 1858, Aaron Y. Baker of Pleasant Valley, went to Ohio and examined the vineyard at Kelley's Island, four hundred acres of which were probably then in bearing. He brought back 30,000 cuttings, and his report of what he saw further stimulated the enterprise of his townsmen. But we can no longer trace the history of individual enterprise. In 1859 and 1860, full two hundred acres of vines were set out. The surface since planted has extended to at least a thousand acres, four hundred of which are already in bearing. The present vineyard region extenas along the hill slopes on the west side of Pleasant Valley, and the west shore of Crooked lake for a distance of ten or twelve miles. The favorite grape is the Catawba. The Isabella is considerably cultivated, but the wine it produces is inferior in quality. An acre of land yields on an average 4,000 pounds of grapes. The prices paid for them per pound in the bulk as they came from the field at the wine cellar presently to be mentioned, have averaged as follows: 


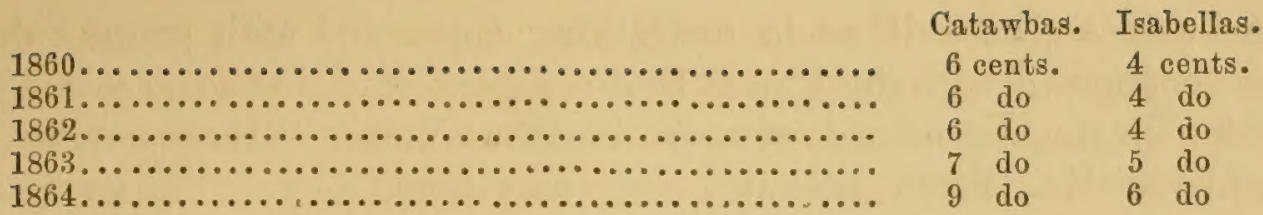

"In 1860 and 1861 the crop was about an average one; in 1862 it was very large-A.Y. Baker's crop and probably some other's yielding 9,300 lbs. to the acre; in 1863 the crop was a little above an average one; in 1864 it was below, but of very fine quality.

"When a vineyard is to be set out, the ground is plowed and trench plowed eighteen or twenty inches deep, the large stones removed, and then it is ready for planting. The vineyards are nearly all on the hill-sides, and frequently where the ascent is decidedly abrupt. Some are plowed into terraces four or five feet wide, but in more of them the vines are planted on the natural surface. In some of them the rows run directly or obliquely up up and down the hills; in others along their sides. The rows are eight feet apart, and the vines seven feet apart in the rows. The roots are set in the spring, and commence bearing in three years; but the third year they only pay expenses. The fourth year the crop is a full one. The vines are fastened to trellises. Ash or chestnut stakes five feet high are set in the ground about twenty-one feet apart in the rows, and they are strung with three No. 12 wires. Some place them about eight feet apart, and use wooden slats instead of wires.

"No manure is used until the vines have been cropped two or three years. Then they receive a very light dressing of well composted barnyard manure; and this is repeated annually on the poorer portions of the vineyard. Even a trifling excess of manure injures the quality of the crop the year it is applied. The vines are pruned almost exclusively by Germans, and according to the German system, except that a little greater length of bearing wood is left. The rule is to allow a fruit bud for every square foot of surface. It is believed that in a good vineyard the vines will last at least one hundred years.

"The picking of early varieties of the grape for the table commences the first of September; for wine about the 10 th of October. It is done by women. The best quality of fruit is first picked for wine, and second is left on the vines and afterwards picked for brandy. The pickers remove with picking-shears all the unripe or imperfect berries, and then place the clusters in boxes or half-barrel tubs. These are carried directly to the wine house, weighed, and accounted for as grain is accounted for in grain warehouses.

"The grapes are first mashed in a wine-mill (Hickock's), and dropped directly into large fermenting vats, or on the press. The larger portion of the wine from the vats and all from the press is drawn directly by means of a hose into wine casks in the cellar. The "mash" (or pommace) which remains behind is left to ferment in the vats, and the succeeding spring is distilled for brandy. The wine in a portion of the vats, however, is left to ferment on the skins for the manufacture of red wines.

"This wine and brandy manufacture was entered upon under the auspices of Mr. John F. Weber, a German of intelligence and much experience 
in the business, as well as in everything connected with grape culture. He was connected with the United States patent office for some years prior to 1860 . In the last named year the Pleasant Valley Wine Company was formed, and Mr. Weber assumed the superintendency of its mechanical and manufacturing affairs. It organized with a capital of $\$ 10,000$ - the corporators being William Baker, Aaron Y. Baker, Charles D. Champlin, Gratton H. Wheeler, I. M. Younglove, D. Rose, G. H. Brundage, E. Brundage, Bell \& McMasters, Dugald Cameron and J. W. Davis. An arched wine vault, a press house, a propagating house, etc., all excellently constructed of stone, were erected about a mile and a half from Hammondsport. Many thought it a very visionary undertaking, but in 1862 the capital stock was doubled. Two or three of the original corporators have sold out. The present directors are the original corporators, with the exception of William Baker, Esq., deceased. The present officers are Gratton H. Wheeler, president and C. D. Champlin, secretary and treasurer.

"The manufactures of the company have been as follows:

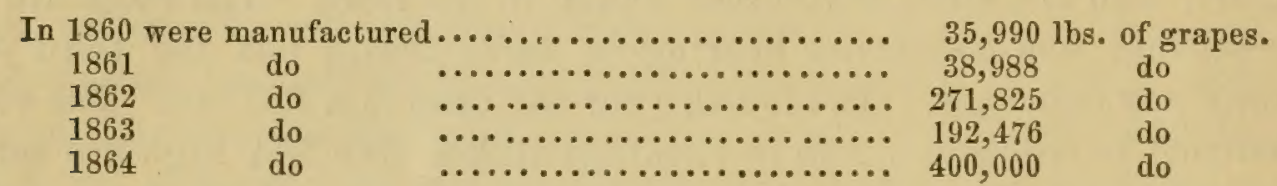

The manufactures of 1864 are not yet completed.

"The wines manufactured are principally of the dry varieties, bearing the names of the Still Catawba, Isabella and Claret. Those of the three first vintages, and most of the fourth, are sold. This year they have commenced making a champagne of Catawba grapes, which is considered a good article. Huge quantities of grapes are put up in boxes and sent away for sale. Several of the most extensive growers are putting up stone storehouses to preserve them through winter for table use.

"Great has been the change effected in the appearance of things and in the value of property in Pleasant Valley hy this new husbandry. The steep hill-sides where the vineyards are now growing luxuriantly would have been prized, a very few years since, as worth not to exceed fifteen or twenty dollars an acre for ordinary agricultural purposes; nor should I now value most of them I passed over at higher than twenty five dollars, or thirty dollars an acre at the outside for such purposes. But in good, eligible situations for grape culture they now command from two hundred dollars to three hundred dollars per acre, and where set with vines and in bearing they command one thousand dollars per acre. The statistics above given were obtained from authoritative sources, and they are reliable."

Your committee have little doubt that there exists other as favorable localities in the State for grape culture as Pleasant Valley, and that they will be improved by the enterprise of our people. The cultivation of the grape has thus far been sufficiently successful to stimulate large additional numbers of our pomologists to its pursuit.

Respectfully,

LEWIS F. ALLEN, of Erie.

JOHN A. KING, of Queens.

ALEXANDER THOMPSON, of Cayuga 



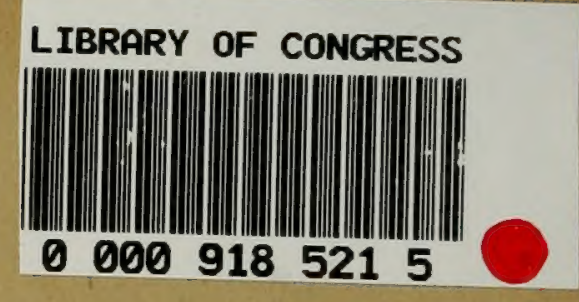

